\title{
ÇİMENTO ESASLI MALZEMELERİN ÇEKME DAYANIMLARINI BULABİLMEK İÇİN YENİ BİR YÖNTEM ÖNERİSİ: ÜÇGEN PLAKA YÖNTEMİ
}

\author{
Hakan T. TÜRKER \\ İskenderun Teknik Üniversitesi, İnşaat Fakültesi, İnşaat Müh. Böl., Eski Havaalanı, İskenderun \\ hakantturker@gmail.com
}

(Geliş/Received: 29.03.2015; Kabul/Accepted: 19.06.2015)

\begin{abstract}
ÖZET
$\mathrm{Bu}$ çalışmada, çimento esaslı malzemelerin çekme dayanımının belirlenmesi için iki eksenli gerilme altında ölçülen yeni bir metot önerilmiştir. $\mathrm{Bu}$ metotta çimento esaslı numuneler eşkenar üçgen plaka şeklinde hazırlanmaktadır. Üretilen üçgen plaka numune, üç adet küçük çelik bilye üzerine mesnetlenmiş ve numunenin üst bölgesinde ağırlık merkezine yerleştirilen küçük çelik bir bilye yardımı ile de yükleme yapılmıştır. Üçgen plaka numunelerin geometrik özellikleri, mesnetlenme ve yükleme durumları belirlenmiş, plaka numunenin taşıma kapasitesi ile malzemenin çekme dayanımı arasında ilişki kurulmuştur. Malzemenin çekme dayanımı için plastisite teorisinin kinematik bir yöntemi olan akma çizgileri yöntemi yardımıyla kapalı formda basit bir analitik formül türetilmiştir. Çekme dayanımını belirleyebilmek için önerilen formülü doğrulamak amacı ile çok sayıda harç üçgen ve prizma numunesi hazırlanarak test edilmiş ayrıca üçgen plaka numuneleri için Sonlu Elemanlar Modelli (SEM) oluşturulmuştur. Deneysel çalışma ve SEM sonuçlarının, önerilen yöntemin iki eksenli çekme dayanımını belirlemede kullanılabileceği görülmüştür. Deneysel sonuçlar, önerilen metotla belirlenen çift eksenli çekme dayanımının üç nokta eğilme deneyiyle belirlenen eğilmede çekme dayanımı değerinden \%22 kadar daha düşük olduğunu göstermiştir.
\end{abstract}

Anahtar Kelimeler: Üçgen plaka yöntemi; iki eksenli çekme dayanımı; çimento esaslı malzemeler; sonlu elemanlar yöntemi; akma çizgisi teorisi

\section{A NEW TEST METHOD FOR BIAXIAL TENSILE STRENGTH OF CEMENT BASED MATERIALS: TRIANGULAR PLATE METHOD}

\begin{abstract}
In this paper, a new test method to determine biaxial flexural tensile strength of cement based materials is proposed. A mortar triangular plate specimen is supported on three small spherical silver balls and loaded externally on a small spherical silver ball from the center of gravity of specimen. Yield line theory (YLT), which is a kinematic method of plastic analysis, is used to drive a simple equation for biaxial flexural tensile strength of cement based materials. In order to verify the derived equation, lots of triangular and prism mortar specimens were produced and tested according to the proposed model and three-point flexural test, respectively. Moreover, finite element analysis is also used to verify the derived equation and the results obtained from the experimental studies. It was concluded that FE analysis and experimental studies verified the proposed method and the derived closed-form equation for biaxial tensile strength of cement based materials. Experimental results also exhibited that biaxial tensile strength measured by proposed method is about $22 \%$ lower than that of the flexural strength obtained from three-point flexural test.
\end{abstract}

Keywords: Triangular plate method; biaxial tensile strength; cement based materials; finite element method; yield line method 


\section{GÍRISŞ (INTRODUCTION)}

Çekme dayanımı, çimento esaslı malzemelerle üretilmiş yapısal elemanların analiz ve tasarımında dikkate alınan önemli bir malzeme özelliğidir [1]. Genellikle doğrudan çekme, yarmada çekme, eğilmede (üç veya dört nokta yükleme) çekme testleri gibi tek eksenli doğrudan veya dolaylı çekme test düzenekleri kullanılarak belirlenmektedir. Doğrudan tek eksenli çekme testi daha doğru ve güvenilir sonuçlar sağlasa da, dolaylı testler (silindir yarma ve eğilmede çekme testleri) doğrudan tek eksenli çekme deneyinin yapma zorluğu nedeniyle, çimento bazlı malzemelerin çekme dayanımını belirlemek için yaygın olarak kullanılır $[2,3]$. Bilindiği üzere tek eksenli çekme deneyi düzeneğinin hazırlanması ve deneyin gerçekleştirilmesi çok zordur. $\mathrm{Bu}$ deney çekme test düzeneği gerektirir, kullanılan aparatlara ve yükleme işlemine karşı çok hassastır [4]. Silindir yarma deneyi ile belirlenen çekme dayanımı, doğrudan çekme dayanımı değerlerine yakın olup, \% 5-12 kadar daha yüksek olduğu bilinmektedir. Buna karşın, kavramsal olarak silindir yarma testi sadece çekme gerilmelerinin oluştuğu bir test yöntemi olmayıp, numunede çekme ve basınç gerilmeleri birlikte oluşmaktadır [4]. Üç veya dört nokta eğilme deneylerinde kirişler kırılana kadar yüklemeye maruz bırakılmaktadır. Kopma modülü olarak bilinen tabandaki teorik maksimum çekme dayanımı; çatlama kesitinde eğilme gerilmesinin doğrusal bir dağılımı olduğu varsayılarak hesaplanır. Bu şekilde belirlenen eğilmede çekme gerilmesi, doğrudan tek eksenli çekme gerilmesi değerlerinden önemli ölçüde yüksektir. Bu artışa muhtemelen gerilme alanındaki betonun doğrusal olmayan gerilme-deformasyon özellikleri neden olmaktadır [5]. Literatürde tek eksenli doğrudan çekme gerilmesi; eğilmede çekme dayanımı değerinin 0,735 katı olduğu belirtilmiştir [6]. Doğrudan çekme ve eğilmede çekme deneylerinde çatlama durumundaki gerilme tek eksenlidir. Silindir yarma deneyinde ise çift eksenlidir, fakat üç asal gerilmenin sadece bir tanesi çekme gerilmesidir [7]. Buna karşın kaplama, döşeme gibi ince plaka formundaki yapılar; geometrileri nedeniyle çok eksenli gerilme durumuna maruzdurlar. Örneğin, beton yollar için teker yükü nedeniyle oluşan gerçek gerilme durumu neredeyse birbirine eşit ve iki eksenli olup tek eksenli olmaktan çok uzaktır. Buna karşın, çimento esaslı malzemelerin çok eksenli davranışları üzerine yapılan çalışmalar; yüksek maliyet, gerçekleştirme zorluğu $[8,9]$ ve çoklu kontrol sistemlerine olan ihtiyaç $[9,10]$ nedeniyle çok azdır [8-10]. Bu nedenle Kim vd. [9] karmaşık deney düzenekleri kullanmadan betonun iki eksenli çekme dayanımı belirleyebilmek için basit bir iki eksenli eğilme deneyi yöntemi önermiş, bu yöntemi İki Eksenli Eğilme (IEE) yöntemi olarak adlandırmıştır. Bu metot üç çelik bilye-üstü-piston (piston-on-three-balls) testi, üç çelik bilye-üstü-bilye (ball-on-three-balls) testi, çember-üstü-çember (ring- on-ring) testi ve çember-üstü-bilye (ball-on-ring) testi gibi cam ve seramik malzemelerin iki eksenli özelliklerini araştırmak için kullanılan deney metotlarından esinlenmiştir $[8,11,12] . \mathrm{Zi}$ vd. [8] belirtilen test metotlarını çimento esaslı malzemeler için uygulanabilir hale getirmiş ve önerdiği deney yönteminde disk şeklinde numune kullanılması gerektiğini belirtmiştir. Seramik malzemelerin çekme dayanımını belirlemek için kullanılan çember-üstüçember (ring-on-ring) test yönteminde kullanılan numunelerin et kalınlığı düşük, narinliği (çap/numune et kalınlığı) yüksektir. IEE yönteminde, disk numune et kalınlığı, disk numune yarıçapı ve et kalınlığı/mesnet bilye yarıçap oranı çimento esaslı numuneler için uygun hale getirilmiştir. Beton numunenin geometrik şekli, plak teorisinde tanımlanan birbirine iki-eksenli çekme davranışını sağlayacak şekilde seçilmiştir. Kirane vd. [13] geliştirmiş oldukları M7 mikro düzlem programını doğrulamak için İEE yöntemini kullanmışlardır. İkieksende oluşan çekme gerilmelerini deney süresince eşit tutabilmek için, yük numune üzerine düzgün yayılı olarak uygulanmalı ve numune yüzeyi tamamen pürüzsüz olmalıdır. Kim vd. [9] numune yüzeyini pürüzsüzleştirmek ve eksantrisiteyi ortadan kaldırmak için; numunenin alt ve üst kısmında çemberle numune arasına dairesel kauçuk katmanı ve $0.3 \mathrm{~mm}$ kalınlığında dört adet teflon tabaka yerleştirmişlerdir. Buna ek olarak, çember ile temas eden numune yüzeyinde yük dağılımının dengeli olmasını sağlamak maksadıyla basınç dayanımı deneyine tabi tutulacak silindir numunelere yapılması gereken kükürt başlık benzeri yüksek mukavemetli alçı hamuru ile başlık uygulanmıştır. Kim vd. [9] tarafindan önerilen İEE metodunda numunelerin test edilebilmesi için teflon ve kauçukların yerleştirilmesi, çemberde yükleme boyunca düzgün yayılı yük etkitilmesini sağlamak büyük çaba gerektirmektedir. Bahsedilen deneysel düzenlemeler ve numune hazırlığı yapılmış olsa dahi eksantrisite problemi, yükleme ve mesnet halkaları kullanımı nedeniyle tam olarak çözülemeyebilir. Çimento esaslı malzemelerin iki eksenli çekme dayanımlarını belirlemek için Kim vd. [9] tarafindan önerilen İEE deney yöntemi yerine üç bilye-üstü-bilye yöntemi (ball-on-three-ball) test kullanımı daha uygun görünmektedir. Üç bilye-üstü-bilye test yöntemi kullanılması durumunda karmaşık test düzenekleri, numune başlıklama ve kauçuk/teflon levha kullanma gibi numune hazırlıklarına gerek yoktur. Buna karşın, üç bilye-üstü-bilye test yönteminde kenar çatlak oluşumuna karşı, mesnet bilyeleri numunenin kenarından belirli bir mesafede iç tarafta yerleştirilmelidir. Mesnet bilyeleri disk numunesinin belirli bir miktar iç kısmına yerleştirildiğinde, disk numunenin yarıçapı ve mesnetlerdeki üç adet çelik bilyelerin halka şeklinde entegre edilmesiyle elde edilen dairenin yarıçapı arasındaki farklılık çekme dayanımı hesaplamalarında dikkate alınmalıdır. $\mathrm{Bu}$ çalışma kapsamında çimento esaslı malzemelerin iki eksenli eğilmede çekme mukavemetini tespit etmek 
amacı ile yeni bir metot olan Üçgen Plaka Yöntemi (ÜPY) önerilmiştir. Bu yöntemde, numuneler üçgen plakalar şeklinde hazırlanmaktadır. Üçgen şeklindeki plaka numunelere yük bilye yardımıyla numunenin ağırlık merkezinden uygulanmakta ve mesnetler üçgenin kenarortaylarının üçte biri noktalarına yerleştirilmektedir. $\mathrm{Bu}$ yolla, mesnetler numune kenarlarından uzak tutularak kenarlarda meydana gelen ezilme kırılmalarının oluşumunun önüne geçilmiştir. Deney numunesinin, düzeneğinin ve çekme dayanımı hesaplanması için türetilen denklemin basitliği iki eksenli çekme dayanımı için önerilen yöntemin önemli avantajlarındandır. Önerilen yöntemin ilk çalışması analitik olarak Akma Çizgileri Yöntemi (AÇY) kullanılarak yapılmıştır. Üçgen plakanın yüklemede kapasitesine ulaştığı noktada çatlak oluşum durumu plakanın mekanizma durumu olarak değerlendirilip çekme mukavemeti formülü çıkartılmıştır. Çıkartılan formülde esas alınan mekanizmanın (akma çizgileri dağılımı) doğruluğunu teyit etmek amaciyla sonlu elemanlar analizi yapılmıştır. Çalışma kapsamında aynı karışımdan hazırlanan üçgen ve prizma numuneler önerilen üçgen plak ve dört nokta eğilme deneylerine tabi tutulmuştur.

\section{2. ÜÇGEN PLAKA YÖNTEMI (TRIANGULAR PLATE METHOD)}

ÜPY numuneler eşkenar üçgen plaka şeklinde hazırlanmaktadır (Şekil 1). ÜPY'nde, üçgen plaka, köşelerden kenarortayların üçte biri mesafede numunenin altından üç noktadan çelik bilye ile mesnetlidir. Yükleme numunenin üst yüzeyinde üçgenin kenarortayların kesiştiği noktada çelik bilye aracılığı ile yapılmaktadır. Mesnet ve yükleme bilyeleri, Şekil 1'de gösterildiği şekilde altıgen somunlar kullanılarak tutturulur. Mesnet olarak kullanılan bilyeler yeterince rijitliğe sahip 100 kN'luk yük taşıma kapasitesine sahiptir [14]. Şekil 2'de önerilen tasarımın şematik görünümü ve deney aşaması gösterilmektedir. Deney prosedürünün basit olması, numune yüzey düzgünlüğü toleransının göreceli olarak daha iyi oluşu ve numune hazırlanmasının kolaylığı ÜPY'nin en önemli avantajlarıdır. Ayrıca, mesnetlerdeki çelik bilyeler ile

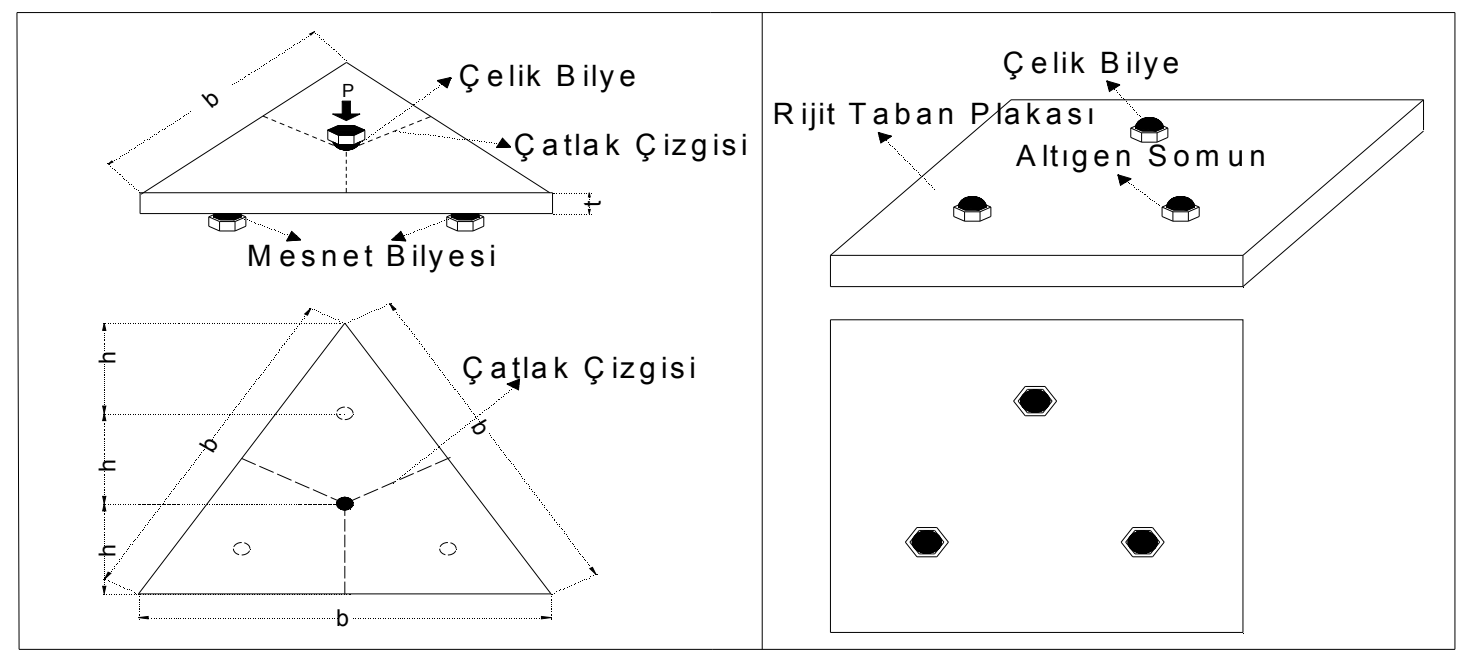

Şekil 1. Üçgen plaka numune ve yükleme taban plakasının geometrisi (Geometry of the triangular plate specimen and loading base plate)
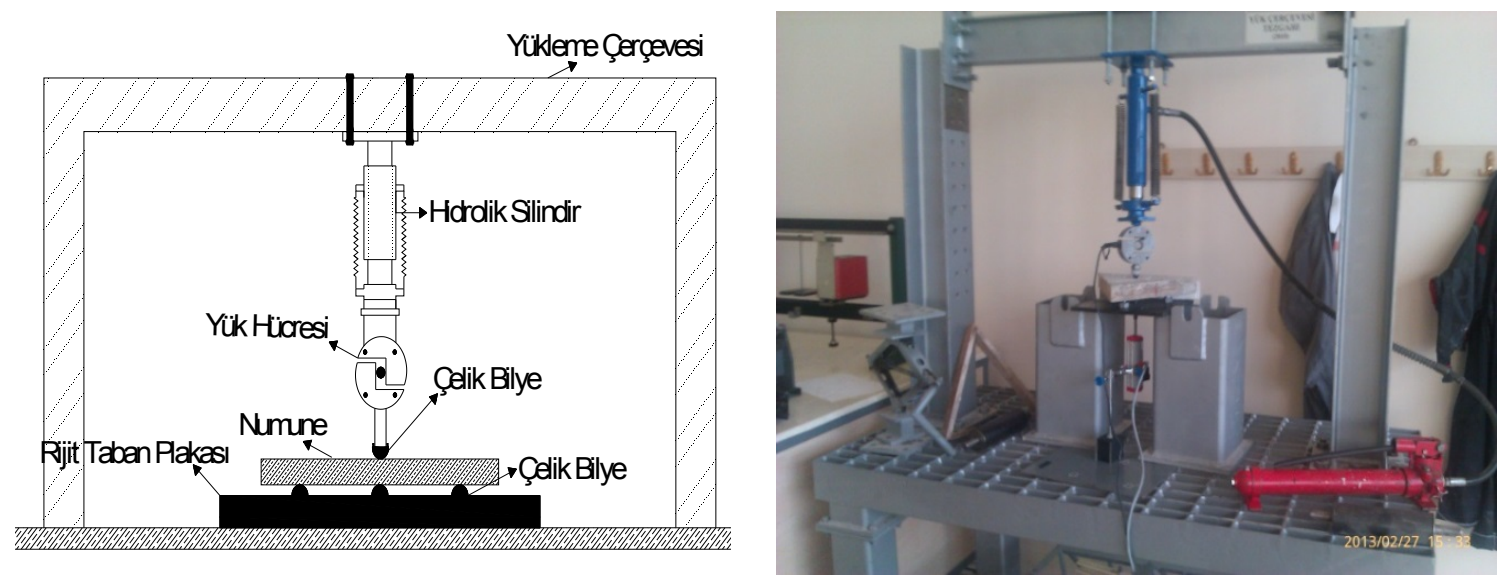

Şekil 2. Deney kurulumu ve üçgen plaka testinin şematik gösterimi (Schematic demonstrations of testing configuration and testing of a triangular plate) 
numune yüzeyi arasındaki temas diğer yöntemlere göre daha az olduğundan sürtünme çok daha az olmaktadır. Deney sonunda, göçme yükü ölçülür, yükleme noktasından üçgenin kenarlarının orta noktalarına uzanan çatlak çizgilerine radyal doğrultularda asal gerilmeler oluşur ve bu gerilme iki eksenli çekme dayanımı olarak tanımlanır [15].

\section{AKMA ÇİGGILERI YÖNTEMİ (YIELD LINE METHOD)}

Çimento esaslı malzemelerin iki eksenli eğilmede çekme dayanımını hesaplamak için, Plastisite teorinin kinematik bir yöntemi olan Akma Çizgisi Yöntemi (AÇY) kullanılmıştır. AÇY betonarme döşeme, plaka ve benzer elemanların tasarımında yaygın olarak kullanılan güçlü bir yöntemdir. AÇY göçme yükü seviyesinde göçme mekanizmasının nasıl gerçekleşeceğini araştırır [16]. Döşemeler veya herhangi bir yapı için, kinematik koşulları sağlayan birden fazla göçme mekanizması olabilir. Ancak bu olası mekanizmalardan sadece bir tanesi en küçük göçme yükünü veren mekanizmadır ve gerçek çözümdür. AÇY alt-limit teoremi gereğince en küçük göçme yükü değerini tespit eden akma çizgisi durumunu araştırır. Mesnetlenme ve yükleme durumu Şekil 1'de gösterilen üçgen plakanın gerçek göçme mekanizması Şekil 3 'te verilmiştir.

AÇY'nde teorik hesaplamalar gerçekleştirmek için aşağıdaki kabuller yapılmıştır:

- Küçük sehim,

- Göçme öncesi kararlı olması,

- Döşemenin herhangi bir kesitinde eğilmeden önce düzlem olan bir kesit eğilmeden sonrada düzlem kalır. Bu kabul sıfır kesme gerilmesiyle sonuçlanır.

- Kesme ve eksenel kuvvetlerin etkisi ihmal edilir. Kesme göçmesi yoktur.

- Doğrusal olmayan dönme kapasitesi

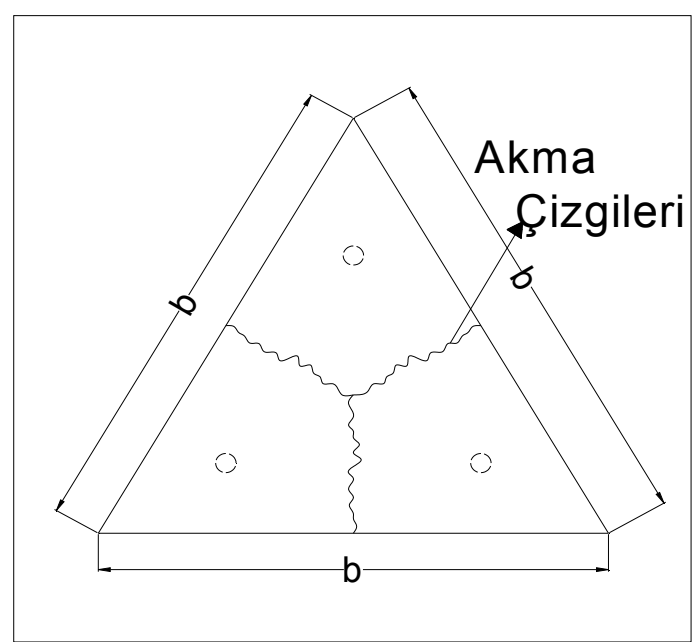

Şekil 3. Kapasitesine ulaşan plaka için kabul edilen göçme mekanizması (Accepted failure mechanisms for ultimate load capacity)
Denklemler türetilirken dikkate alınan kabullerde belirtildiği gibi AÇY döşemenin doğrusal olmayan dönme kapasitesine sahip olması gerekmektedir. AÇY rijit-plastik ve elastik-mükemmel plastik malzemeler için çok güçlü bir yöntemdir. AÇY doğrusal olmayan dönme kapasitesine sahip olduklarından betonarme döşemelerde başarıyla uygulanmaktadır. Donatısız, gevrek davranış sergileyen beton plakada doğrusal olmayan bir dönme kapasitesinin oluşması beklenmez. Doğrusal olmayan dönme kapasitesi talebi, döşemede önce kapasitesine ulaşan kesitler moment kapasitelerini kaybetmeden, sistemde moment transferinin gerçekleşmesi ve mekanizma oluşmasına müsaade etmesi için gereklidir. Üçgen plaka için öngörülen göçme mekanizma durumunda, akma çizgileri boyunca elastik gerilme dağılımı düzgün yayılı olduğundan, öngörülen akma çizgileri boyunca kesitlerde hemen hemen aynı zamanda moment kapasitesine ulaşılarak göçme mekanizması gerçekleşmektedir. Mekanizmanın gerçekleşmesi için önemli bir moment aktarım gereksinimi olmadığından, AÇY'nin yükleme ve mesnetlenme durumu belirli olan üçgen plakalar için kullanılabileceği düşünülmüştür. Deneylerden elde edilen sonuçlar bu kabulün doğruluğunu teyit etmiştir. Şekil 3'teki göçme mekanizma durumu dikkate alınarak enerji teoremi gereğince, iç iş, diş işe eşitlenerek göçme anında, kesitteki maksimum çekme gerilmesi aşağıdaki denklemle bulunur.

$\sigma_{t}=\frac{2 P}{t^{2} \sqrt{3}}$

Denklemde P maksimum yük (göçme Yükü), t üçgen plaka et kalınlığı, $\sigma_{t}$ malzemenin iki eksenli çekme dayanımıdır. Denklemden görüldüğü üzere çekme dayanımı, üçgen plakanın et kalınlığ̀ ve göçme yükü değerine bağlıdır. Çekme dayanımının üçgen numunenin kenar uzunluklarına bağlı olmadığı anlaşılmaktadır. Bunun anlamı aynı kalınlıkta farklı boyuttaki üçgen numunelerle aynı sonuç edileceğidir.

\section{SEM İLE GERİLME DAĞILIMININ BELİRLENMESİ (DETERMINATION OF STRESS FIELD USING FEM)}

ÜPY'nde önerilen mesnetlenme ve yükleme durumu dikkate alınarak üçgen plakaların SEM ile elastik analizi yapılmıştır. SEM yöntemi ile elastik analiz yapmaktaki maksat Bölüm 1. 2 de önerilen çekme dayanımı denklemi türetmek için dikkate alınan kabullerin doğruluğunu teyit etmek, üçgen plakanın önerilen yükleme koşulları altındaki elastik davranışı ve çatlak gelişiminin nasıl gerçekleşebileceğini belirlemektir. SEM, SAP2000 paket programı kullanılarak yapılmıştır. Plakayı modellemek için dört noktalı shell elemanlar kullanılmıştır. Mesnetler Şekil 1 'de gösterilen noktalarda düşey doğrultuda tutulu, yatay iki eksende serbest olarak tanımlanmıştır. Modelde malzemenin Elastisite modülü 27,5 GPa, poison oranı 0,2 olarak alınmıştır. Yükleme, üçgen 
plakanın üst yüzeyinde üçgenin ağırlık merkezine tekil yük olarak uygulanmıştır. Modelin çözümünden, plaka tabanında oluşan asal gerilme dağılımı Şekil 4 'te gösterilmiştir.

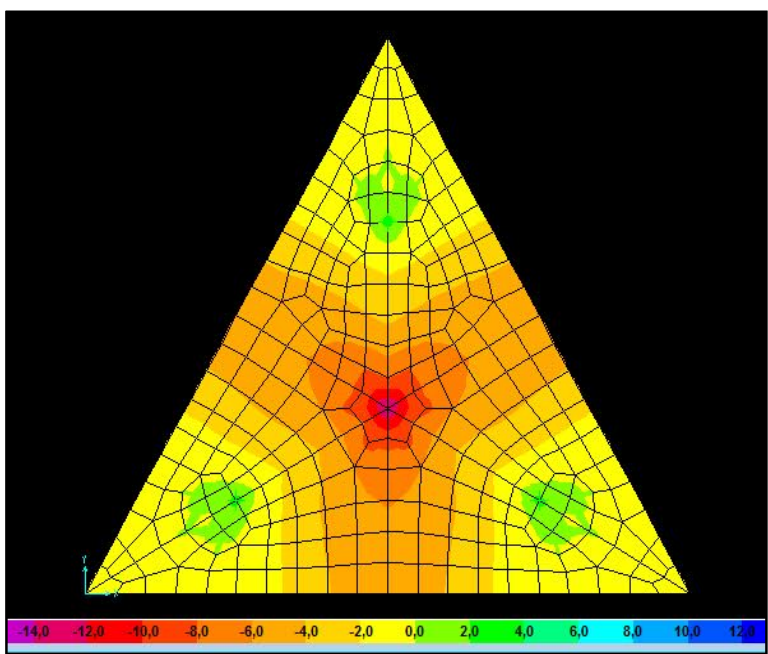

Şekil 4. Üçgen plaka deney numunesinin taban yüzeyinin maksimum asal gerilme dağılımı (Contour plot of the maximum principal stress on the bottom surface of a triangular plate test specimen)

Renklendirilmiş asal gerilme durumundan (Şekil 4) üçgen plaka için yapılan başlıca gözlemler aşağıda sıralanmıştır:

- Yükün uygulandiğı noktada ve mesnetlerde bölgesel gerilme yığglmaları gözlemlenmiştir.

- Oluşan asal gerilme eksenel simetrik karakteristiğe sahiptir.

- Mesnet bölgelerinde basınç gerilmeleri oluşmuştur (yeşil bölgeler).

- Gerilme yığılmalarının oluştuğu yükleme noktası haricinde, maksimum çekme gerilmeleri üçgenin kenarlarının ortasından hat boyunca yükleme noktasına doğru düzgün yayılmaktadır.

- Üçgen plaka üzerindeki asal gerilme dağılımı AÇY'nde öngörülen mekanizma durumuyla uyumludur.

\section{DENEYSEL ÇALIŞMALAR (EXPERIMENTAL STUDIES)}

Önerilen ÜPY'nin performansını değerlendirebilmek için bir seri deneyler yapılmıştır. Ayrıca karşılaştırma amaçlı olarak eğilme gerilmesi üç nokta eğilme deneyiyle de tespit edilmiştir. Bu amaçla her bir deney yöntemi için 18 ve toplamda 36 adet olmak üzere, üçgen plaka ve prizmatik harç numuneler imal edilmiştir. ÜPY için $4 \mathrm{~cm}$ kalınlığında ve kenar uzunluğu $30 \mathrm{~cm}$ olan eșkenar üçgen numuneler imal edilmiştir. Üç nokta eğilme testi içinse, 4x4x16 cm prizmatik numuneler imal edilmiştir. Harç numunelerin basınç dayanımını belirlemek için 6 adet 10x10x10 cm küp numune hazırlanmıștır. Her iki faklı şekilli deney numunesinde de aynı malzeme ve aynı karışım kullanılmıştır. Üretilen harç karışımlarının su-çimento oranı (s/ç) 0.485 olup, çimento -kum oranı ise 1:2,75 dir. Harç üretilirken CEM I 42,5 R Portland çimentosu, maksimum tane boyutu $4 \mathrm{~mm}$ olan dere kumu ve kırma kum kullanılmıştır. Üretilen numuneler kalıbında bir gün süreyle laboratuvar koşullarında bekletilmiş, kalıptan çıkarılan numuneler ise 28 gün boyunca suda kür edilmiştir. Altı numunenin 28 günlük ortalama basınç dayanımı 37,5 MPa olarak belirlenmiştir.

\section{SONUÇLAR VE TARTIŞMALAR (RESULTS AND DISCUSSION)}

\subsection{Kırılma Davranışı (Faılure Pattern)}

Üçgen ve prizma numunelerin kırılma şekilleri Şekil 5'te gösterilmektedir. Üç nokta eğilme deneyine tabi tutulan numuneler, beklendiği gibi kiriş tabanından yukarı doğru yayılan çatlaklar nedeniyle kırılmıştır (Şekil 5a). Üçgen plakalar, Şekil 3'de gösterildiği gibi AÇY'nde dikkate alınan akma çizgilerine çok benzer çatlaklar oluşturarak kırılmıştır. Bu kırılma düzeni AÇY de öngörülen mekanizmanın gerçek mekanizma olduğu sonucunu doğurmaktadır. Çatlakların üçgenin ağırlık merkezine eksenel simetrik olarak oluştuğu görülmektedir. Sonuçlar SEM elde edilen asal gerilme dağılımıyla da uyumludur.
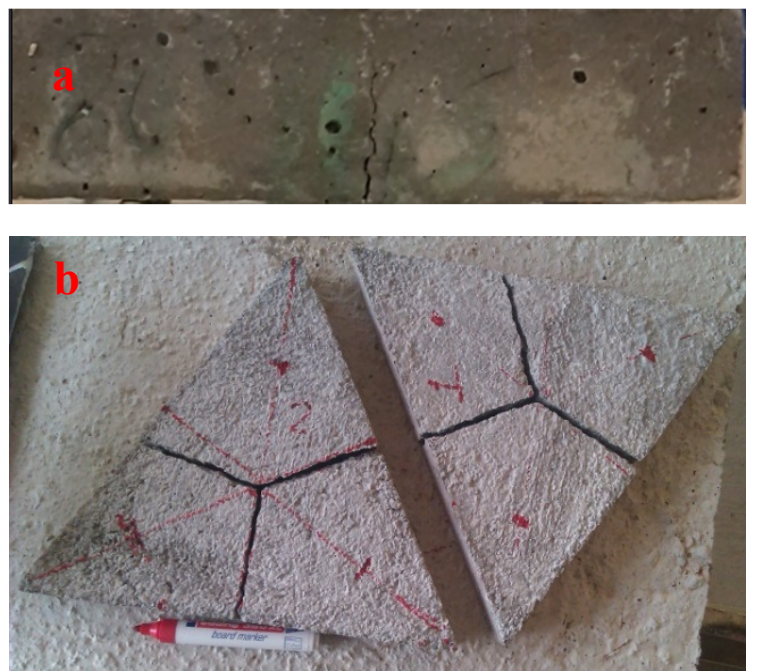

Şekil 5. Kırılma davranışı (a) Üç nokta eğilme yöntemi (b) Üçgen plaka yöntemi (The failure patterns of (a) The three-point bending test specimen and (b) The Modified ball-on-three-ball test specimen)

Şekil 4'de görüldüğü üzere sonlu elamanlar analizinde, yükleme ve mesnet noktalarında bölgesel gerilme yığılmaları görülmektedir. Deney süresince yük ve çatlak oluşumu dikkatlice gözlemlenmiştir. Deney sirasinda ve sonrasinda numuneler incelendiğinde tekil yükün ve mesnet noktalarının çevresinde herhangi bir çatlak ve/veya ezilme görülmemiştir. SEM'nde gözlemlenen bölgesel gerilme yığılmalarının üçgen plakanın genel davranışını etkilemediği görülmüştür. 
Tablo 1. Deneysel test sonuçları (Experimental test results)

\begin{tabular}{|c|c|c|c|c|}
\hline \multirow{3}{*}{ No } & \multicolumn{2}{|c|}{ Üçgen plaka yöntemi } & \multicolumn{2}{|c|}{ Üç nokta eğilme yöntemi } \\
\hline & \multicolumn{2}{|c|}{ Üçgen plaka (b=30 cm; $t=4 \mathrm{~cm})$} & \multicolumn{2}{|c|}{ Prizma $(4 \times 4 \times 16 \mathrm{~cm})$} \\
\hline & $\begin{array}{c}\text { Maksimum } \\
\text { yük }(\mathrm{kN})\end{array}$ & Çekme dayanımı (MPa) & Maksimum yük(kN) & $\begin{array}{c}\text { Çekme dayanımı } \\
\text { (MPa) }\end{array}$ \\
\hline 1 & 8,46 & 6,11 & 3,21 & 7,52 \\
\hline 2 & 8,00 & 5,77 & 3,34 & 7,83 \\
\hline 3 & 8,41 & 6,07 & 3,27 & 7,66 \\
\hline 4 & 7,27 & 5,25 & 3,43 & 8,04 \\
\hline 5 & 8,77 & 6,33 & 3,64 & 8,53 \\
\hline 6 & 8,53 & 6,16 & 3,57 & 8,37 \\
\hline 7 & 9,23 & 6,66 & 3,71 & 8,70 \\
\hline 8 & 8,15 & 5,88 & 3,24 & 7,59 \\
\hline 9 & 8,91 & 6,43 & 3,25 & 7,62 \\
\hline 10 & 8,55 & 6,17 & 3,33 & 7,80 \\
\hline 11 & 8,23 & 5,94 & 3,19 & 7,48 \\
\hline 12 & 8,38 & 6,05 & 3,41 & 7,99 \\
\hline 13 & 8,57 & 6,18 & 3,39 & 7,95 \\
\hline 14 & 7,98 & 5,76 & 3,26 & 7,64 \\
\hline 15 & 9,01 & 6,50 & 3,51 & 8,23 \\
\hline 16 & 8,63 & 6,23 & 3,48 & 8,16 \\
\hline 17 & 8,71 & 6,29 & 3,19 & 7,48 \\
\hline$\frac{18}{\text { Ortalama }}$ & $-\frac{8,25}{8,45}$ & $--\frac{5,95}{6,10}=-$ & $\frac{3,35}{3,38}-=$ & $-\frac{7,85}{7,91}-$ \\
\hline St. sapma & 0,44 & 0,32 & 0,16 & 0,36 \\
\hline Varyasyon & 0,19 & 0,10 & 0,02 & 0,13 \\
\hline
\end{tabular}

\subsection{Deney Sonuçları (Results of Experimental Studies)}

Üçgen ve prizmatik numuneler sırasıyla ÜPY ve üç nokta eğilme testlerine tabi tutulmuştur. Yapılan bu deneylerden belirlenen göçme yükleri ve bu yükler kullanılarak elde edilen çekme dayanım değerleri Tablo 1 de verilmiştir. Çekme dayanımları, göçme yüklerinin ÜPY için türetilen denklemde yerine konulması ile hesaplanmıştır. Üç nokta eğilme deneyinde çekme dayanımı aşağıdaki formül kullanılarak hesaplanmıştır.

$\sigma_{t}=\frac{3 P L}{2 B D^{2}}$

$P$ : maksimum yük, $L$ : yükleme açıklığı, $B$ : prizma kalınlığı ve $D$ : prizma derinliği.

Çekme dayanımı sonuçları dikkatlice değerlendirildiğinde; üçgen plaka numunelerden elde edilen ortalama iki eksenli çekme dayanımının; prizmatik numunelerden elde edilen ortalama çekme dayanımından düşük olduğu görülmektedir. Genel olarak çekme dayanımı sırasıyla iki eksenli ve tek eksenli deneyler için 5,25 ile 6,66 $\mathrm{MPa}$ a ve 7,48 ile 8,70 MPa a arası değişiklik göstermektedir. Teste tabi tutulmuş 18 adet üçgen plaka numunenin ortalama iki eksenli çekme dayanımı 6,10 MPa iken, teste tabi tutulmuş 18 adet prizmatik numunenin ortalama eğilmede çekme dayanımı 7,91 MPa dır. Üç nokta eğilme deneyinden elde edilen ortalama çekme dayanımı ile iki eksenli çekme dayanımı (üçgen plaka testi) karşılaştırıldığında, oran (iki eksenli eğilme/tek eksenli eğilme) $0,77^{\prime}$ dir. Üç nokta eğilme testi ve ÜPY testlerinden elde edilen standart sapma (SS) ve varyasyon katsayıları (COV) sirasıla 0,36 (SS), 0,13 (COV) ve 0,32 (SS), 0.10 (COV). Daha önce belirtildiği üzere, maksimum tek eksenli doğrudan çekme dayanımı, üç nokta eğilmede çekme dayanımının 0,735 katıdır. Deney sonuçları, önerilen ÜPY'nin çimento esaslı malzemelerin iki eksenli gerilme dayanımının belirlenmesinde pratik ve güvenilir bir yöntem olduğunu göstermekte olup, ayrıca önerilen bu yöntem doğrudan çekme dayanımına daha yakın çekme dayanımı değeri vermektedir. 


\section{SONUÇLAR (CONCLUSIONS)}

Çalışma sonucunda aşağıda sıralanan sonuçlara ulaşılmıştır.

Önerilen üçgen plaka yöntemi çimento esaslı malzemelerin iki eksenli çekme dayanımının belirlenmesine yönelik basit ve güvenilir bir yöntem olduğu görülmüştür. Önerilen üçgen plaka yönteminde numune ve deney düzeneği hazırlaması ve uygulanması çok kolaydır. Üçgen plaka numunenin göçme yük kapasitesi durumu için AÇY kullanılarak çimento esaslı malzemelerin iki eksenli çekme dayanımı hesaplanması için basit ve kullanışlı bir denklem elde edilmiştir. AÇY'nde bulunan akma çizgisi durumu (mekanizma durumu) sonlu elemanlar analizinde hesaplanan asal gerilme dağılımıyla uyumlu olduğu gösterilmiştir. AÇY'nde dikkate alınan mekanizma durumunun (kapasite durumunda oluşan çatlakların dağılımın) gerçek çözüm olduğu teyit edilmiştir. ÜÇY'nde çekme dayanımı için bulunun denklem, göçme yükü ve plak yüksekliğine bağlıdır. $\mathrm{Bu}$ durum farklı boyutlarda numune hazırlama imkânı vermektedir. ÜÇY'nin daha büyük numunelerle çimento esaslı malzemeler içinde rahatlıkla kullanılabileceği düşünülmektedir. Deneysel sonuçlar; önerilen üçgen plaka yöntemi ile ölçülen iki eksenli çekme dayanımının üç nokta eğilme testi ile bulunan eğilme dayanımından yaklaşık olarak \% 22 daha düşük olduğunu göstermektedir. Tek eksenli doğrudan çekme dayanımı testinden elde edilen çekme dayanımı, üç nokta eğilmede çekme dayanımının 0,735 katı daha düşük olduğundan, üçgen plaka deneyi ile bulunan eğilmede çekme dayanımının doğrudan çekme deneyi ile bulunan çekme dayanımı değerine daha yakın olduğu sonucu çıarılmıştır. Üçgen plaka deneylerinde üçgen numunelerin kırılma düzeni öngörülen mekanizmasıyla aynı olması, elde edilen çekme dayanımı sonuçlarındaki standart sapma ve varyasyon katsılarının küçük olması yöntemin güvenirliğini göstermektedir. Üçgen plaka yönteminin iki eksenli gerilme durumunu dikkate alması, tek eksenli çekme durumuna göre daha gerçekçi olduğu düşünülmektedir.

\section{KAYNAKLAR (REFERENCES)}

1. Denneman, E., Kearsley, E.P., Visser, A.T, "Splitting Tensile Test For Fibre Reinforced Concrete", Materials and Structures, Cilt 44, No 8, 1441-1449, 2011.

2. Mallat, A., ve Alliche, A., "A Modified Tensile Test to Study the Behaviour of Cementitious Materials", Strain, Cilt 47, No 6, 499-504, 2011.

3. Li, D., Wong, L. N. Y., "The Brazilian Disc Test for Rock Mechanics Applications, Review and New Insights", Rock Mech Rock Eng, Cilt 46, No 2, 269-287, 2013.
4. Katsaragakis, E. S., "A New Tensile Test For Concrete", Materials and Structures, Cilt 20, No 6, 463-466, 1987.

5. Wu, S., Chen, X., Zhou, J., “Tensile Strength of Concrete Under Static and Intermediate Strain Rates: Correlated Results From Different Testing Methods", Nuclear Engineering and Design, Cilt 250, 173-183, 2012.

6. Wright, P.J.F., "The Effect Of The Method Of Test On The Flexural Strength Of Concrete", Magazine of Concrete Research, Cilt 4, No 11, 67-76, 1952.

7. Zi, G., Kim, J., ve Bazant, Z. P., "Size Effect on Biaxial Flexural Strength of Concrete", ACI Materials Journal, Cilt 111, No 3, 319-326, 2014.

8. Zi, G., Oh, H., Park, S-K., "A Novel Indirect Tensile Test Method to Measure The Biaxial Tensile Strength of Concretes and Other Quasibrittle Materials", Cement and Concrete Research, Cilt 38, No 6, 751-756, 2008.

9. Kim, J., Kim, D. J., Zi, G., "Improvement of The Biaxial Flexure Test Method For Concrete", Cement \& Concrete Composites, Cilt 37, No 1, 154-160, 2013.

10. Kupfer, H., Hubert, KH., Hubert, R., "Behavior of Concrete Under Biaxial Stresses", Journal of American Concrete Institute, Cilt 66, No 8, 656-666, 1969.

11. Lee, S. K., Song, Y. C., ve Han, S. H., "Biaxial Behavior of Plain Concrete of Nuclear Containment Building", Nuclear Engineering and Design, Cilt 227, No 2, 143-153, 2004.

12. Muzyka, N. R.," Equipment For Testing Sheet Structural Materials Under Biaxial Loading. Part 2. Testing by Biaxial Loading in the Plane of the Sheet", Strength of Materials, Cilt 34, No 2, 206-212, 2002.

13. Kirane, K., Bazant, Z. P., Zi, G., "Fracture and size effect on strength of plain concrete disks under biaxial flexure analyzed by microplane model M7', Journal of Engineering Mechanics, Cilt 140, No 3, 604-613, 2014.

14. ASTM C1550-05 (2005), Standard Test Method for Flexural Toughness of Fiber Reinforced Concrete (Using Centrally Loaded Round Panel), ASTM International, 100 Barr Harbor Drive, PO Box C700, West Conshohocken, PA 194282959, United States.

15. Danzer, R., Harrer, W., "Supancic, P., Lubea, T., Wang, Z., Borger A., The Ball On Three Balls Test-Strength And Failure Analysis Of Different Materials", Journal of the European Ceramic Society, Cilt 27, No 3, 1481-1485, 2007.

16. Kennedy, G. ve Goodchild, $\mathrm{CH}$, Pratical Yield Line Design, Concrete Centre, Surrey, UK, . 2004. 
